\section{Outcomes of surgery in children with early-onset exotropia}

SY Suh ${ }^{1,2}$, MJ Kim ${ }^{1,2}$, J Choi ${ }^{3}$ and S-J Kim ${ }^{1,2}$
${ }^{1}$ Department of Ophthalmology, Seoul National University College of Medicine, Seoul, Korea

${ }^{2}$ Seoul Artificial Eye Center, Seoul National University Hospital Clinical Research Institute, Seoul, Korea

${ }^{3}$ Department of Ophthalmology, Inje University Sanggye Paik Hospital, Seoul, Korea

Correspondence: S-J Kim, Department of Ophthalmology, Seoul National University College of Medicine, 28 Yeongeondong, Chongno-gu, Seoul 110-744, Korea

Tel: + 8222072 2438;

Fax: + 8227413187 .

E-mail: ophjun@snuh.ac.kr

Received: 18 June 2012 Accepted in revised form: 18 February 2013 Published online: 26 April 2013

\begin{abstract}
Objective To evaluate the clinical characteristics and surgical outcomes of early-onset exotropia and to compare differences between constant and intermittent exotropia at presentation. Methods The medical records of 45 exotropia patients with a reported onset before 1 year of age who were operated on between 2008 and 2011 were reviewed, and the clinical characteristics and surgical outcomes of these patients were analyzed retrospectively. Patients were then divided into two groups according to type of exotropia at presentation: a constant (XT) group and an intermittent $(X(T))$ group. Clinical features and surgical results of exotropia were then compared between these two groups. Results The mean age of onset of exodeviation in 45 patients was $9.3 \pm 3.8$ months. Mean age at surgery was $4.5 \pm 2.4$ years, and the mean postoperative follow-up period was 17.3 months (range, 6-37 months). Of the 45 patients, $67 \%$ showed alignment of less than \pm 10 prism diopters (PD) at final visit. Gross stereopsis was achieved in all 34 testable patients, and bifixation developed in 10 patients (29\%). Eleven patients were included in XT group and 34 patients in X(T) group. No significant intergroup difference was found between surgical success rates and binocularities.

Conclusion Surgical outcomes, both motor and sensory, were not poor in early-onset exotropia patients, even in patients with constant deviation. Good binocular results following surgery can be achieved in children presenting with apparently constant early-onset exotropia.

Eye (2013) 27, 836-840; doi:10.1038/eye.2013.75; published online 26 April 2013
\end{abstract}

Keywords: Early-onset exotropia; infantile exotropia; surgical outcome; binocularity
Introduction

Surgical treatment of intermittent exotropia or constant exotropia, preceded by a period of intermittency, is directed at normalization of binocular function. ${ }^{1}$ It is reported that there is a greater chance of maintaining high-grade stereopsis when surgical alignment is performed at a younger age, after a shorter duration of exotropia, or while the exotropia remains intermittent. ${ }^{2}$

Exotropia in a healthy child younger than 1 year of age is known to be rare, and only limited studies are done on early-onset exotropia. ${ }^{3-5}$ Unlike older children with intermittent exotropia, few patients presenting with onset of exotropia during the first year of life ultimately achieved high-grade stereopsis, even after early surgical correction. ${ }^{3-5}$

In this study, we evaluated early-onset exotropia patients who underwent surgery, and compared the clinical features and surgical outcomes of patients with constant exotropia and intermittent exotropia at presentation.

\section{Materials and methods}

The records of patients with a reported onset of exotropia before 1 year of age who underwent surgery at Seoul National University Hospital from December 2008 to September 2011 were reviewed retrospectively. Patients with any history of previous eye muscle surgery were excluded, as were patients followed for $<6$ months. Patients were also excluded if they had any other ocular or systemic diseases such as a neurologic disorder or genetic defect. Informed written consent for the surgical procedures was obtained from all patients and their parents. The following information was recorded when available: age at onset, gender, preoperative angle of exotropia, age at surgery, 
surgical outcomes, binocular sensory status, and the presence of associated ocular motility disorders or systemic diseases.

Age at onset was considered as the age at which a parent or guardian first noticed an ocular misalignment, and this was confirmed by checking past photographs of the patient. Initial angle of deviation was measured for fixation at $1 / 3$ and $6 \mathrm{~m}$ using the alternate prism cover test in most patients. The Krimsky method was used when patients were too young or their cooperation was too poor for the alternate prism cover test. The angle of deviation was measured on at least three different visits to get reliable measurements.

All patients were checked for coexisting ocular conditions, such as manifest or latent nystagmus, dissociated vertical deviation (DVD), and inferior/ superior oblique muscle overaction (SOOA). The Worth4-dot test and the Titmus test were performed on cooperative patients to assess binocular sensory status. Gross stereopsis was defined as perception of the stereo fly on the Titmus test.

Surgery was recommended in patients with constant deviation at presentation and when the frequency or magnitude of exotropia deteriorated in patients with intermittent deviation. Part-time occlusion therapy was attempted in patients with small-angle exodeviation, and in those whose parents wanted to postpone surgical intervention.

All surgeries were performed under general anesthesia by a single surgeon (SJK), using the surgical formula based on the surgeon's experience (Table 1). Surgical dosage was based on the angle of distant deviation. Patients underwent unilateral/bilateral lateral rectus muscle recession or unilateral recession-resection for exotropia. Besides surgery for exotropia, inferior oblique muscle weakening surgery (marginal myotomy or myectomy) or superior oblique posterior tenectomy was performed together for prominent oblique muscle overaction, and superior rectus muscle recession was performed for manifest DVD.

Postoperative alignments at distance and near were measured in the immediate postoperative period, at 1, 6, and 12 months after surgery, and at last visits. Patients were divided into constant or intermittent exotropia groups according to alignment at presentation, and the two groups were compared with respect to clinical characteristics and surgical outcomes.

Statistical analysis was performed using SPSS for Window version 19.0 (SPSS, Chicago, IL, USA).

Mann-Whitney test was used to compare the preoperative angle of deviations between two groups. The independent $t$-test was used to compare other mean values, and Fisher's exact test was used to compare categorical variables. Two-tailed $P$-values of $<0.05$ were
Table 1 Surgical dosage used for exotropia in this study

\begin{tabular}{lccc}
\hline Prism diopters & $B L R, m m$ & $R \mathcal{E}, m m$ & ULR, $m m$ \\
\hline 15 & 4 & & 8 \\
20 & 5.5 & $5 / 4$ & 9 \\
25 & 6 & $6 / 4$ & 9.5 \\
30 & 6 & $6 / 5$ & \\
35 & 7 & $7 / 5$ & \\
40 & 8 & $8 / 5$ & \\
45 & 9 & $8 / 6$ & \\
50 & 9.5 & $9 / 6$ & \\
\hline
\end{tabular}

Abbreviations: BLR, bilateral lateral rectus muscle recession; R\&R, recession and resection procedure of one eye; ULR, unilateral lateral rectus muscle recession.

The surgical doses used for treatment of exotropia in this study were based on the surgeon's experience.

considered statistically significant. This study was approved by the Institutional Review Board of the Seoul National University Hospital, which was conducted in accordance with the Declaration of Helsinki.

\section{Results}

Forty-five patients were included in the study. Eleven patients (24\%) presented with constant deviation (XT group) and 34 patients (76\%) with intermittent deviation (X(T) group). The mean age of onset of exodeviation was $9.3 \pm 3.8$ months in all study subjects, $8.5 \pm 3.7$ months in the XT group, and $9.5 \pm 3.8$ months in the $\mathrm{X}(\mathrm{T})$ group. Mean age at first visit for the 45 study subjects was $3.7 \pm 2.3$ years, and in the $\mathrm{XT}$ group and $\mathrm{X}(\mathrm{T})$ group were $4.0 \pm 3.0$ and $3.6 \pm 2.1$ years, respectively. The mean age at surgery for all study subjects was $4.5 \pm 2.4$ years, and in the $\mathrm{XT}$ and $\mathrm{X}(\mathrm{T})$ groups were $4.4 \pm 3.0$ and $4.6 \pm 2.2$ years, respectively. Mean follow-up period for all study subjects was $17.3 \pm 9.3$ months (range, 6-37 months), and in the $\mathrm{XT}$ and $\mathrm{X}(\mathrm{T})$ groups were $15.7 \pm 10.6$ months (range, 6-37 months) and 17.8 \pm 8.9 months (range, 6-36 months), respectively. No significant intergroup difference was found for mean age at onset of exodeviation, age at surgery, age at first visit, or follow-up period ( $P>0.05$ for all comparisons).

Mean preoperative exodeviation at distance in 44 of the 45 study subjects was $31.8 \pm 7.8 \mathrm{PD}$; range, 20-50 PD), and in the $\mathrm{XT}$ and $\mathrm{X}(\mathrm{T})$ groups were $34.8 \pm 9.1 \mathrm{PD}$ (range, 25-50 PD) and 30.8 \pm 7.3 PD (range, 20-45 PD), respectively. Mean preoperative exodeviation at near in all study subjects was 32.9 \pm 9.4 PD (range, 12-50 PD), and in the $\mathrm{XT}$ and $\mathrm{X}(\mathrm{T})$ groups was $37.5 \pm 9.6 \mathrm{PD}$ (range, 25-50 PD) and 31.5 \pm 9.0 PD (range, 12-50 PD), respectively. Preoperative exodeviation at distance and near were both larger in the XT group, but not significantly different in two groups.

Surgical outcomes in the two groups are summarized in Table 2. When orthophoria or an alignment of less 
Table 2 Basic characteristics and surgical outcomes of the patients

\begin{tabular}{|c|c|c|c|c|}
\hline & Entire group $(\mathrm{n}=45)$ & Constant XT $(\mathrm{n}=11)$ & Intermittent XT $(\mathrm{n}=34)$ & P-value \\
\hline Gender (M:F) & $13: 32$ & $5: 6$ & $8: 26$ & 0.251 \\
\hline Age of onset (months) & $9.3 \pm 3.8(0 \sim 12)$ & $8.5 \pm 3.7(3 \sim 12)$ & $9.5 \pm 3.8(0 \sim 12)$ & 0.431 \\
\hline Age of first visit (years) & $3.7 \pm 2.3(0.4 \sim 9.0)$ & $4.0 \pm 3.0(0.8 \sim 9.0)$ & $3.6 \pm 2.1(0.4 \sim 8.4)$ & 0.601 \\
\hline Age at surgery (years) & $4.5 \pm 2.4(1.0 \sim 9.3)$ & $4.4 \pm 3.0(1.2 \sim 9.3)$ & $4.6 \pm 2.2(1.0 \sim 9.1)$ & 0.820 \\
\hline \multicolumn{5}{|l|}{ Preoperative deviation } \\
\hline Distance (PD) & $31.8 \pm 7.8(20 \sim 50)$ & $34.8 \pm 9.1(25 \sim 50)$ & $30.8 \pm 7.3(20 \sim 45)$ & 0.237 \\
\hline Near (PD) & $32.9 \pm 9.4(12 \sim 50)$ & $37.5 \pm 9.6(25 \sim 50)$ & $31.5 \pm 9.0(12 \sim 50)$ & 0.084 \\
\hline \multicolumn{5}{|c|}{ Postoperative 6-month deviation $<10$ PD } \\
\hline Distance (\%) & 73 & 90 & 68 & 0.241 \\
\hline Near $(\%)$ & 71 & 82 & 68 & 0.467 \\
\hline \multicolumn{5}{|l|}{ Final deviation $<10 P D$} \\
\hline Distance (\%) & 67 & 82 & 62 & 0.288 \\
\hline Near $(\%)$ & 62 & 73 & 59 & 0.765 \\
\hline Reoperations & 5 & 0 & 5 & \\
\hline Follow-ups (months) & $17.3 \pm 9.3(6 \sim 37)$ & $15.7 \pm 10.6(6 \sim 37)$ & $17.8 \pm 8.9(6 \sim 36)$ & 0.247 \\
\hline
\end{tabular}

Abbreviations: PD, prism diopters; XT, exotropia.

${ }^{*} P$-value refers to intermittent versus constant $\mathrm{XT}$.

than \pm 10 PD at distance was regarded as surgical success, the success rate at 6 months postoperatively was $73 \%(33 / 45)$ in all study subjects, and 91\% (10/11) and $68 \%(23 / 34)$ in the XT and X(T) groups, respectively. At final visits, success rates in all study subjects and the XT and $\mathrm{X}(\mathrm{T})$ groups were $67 \%(30 / 45), 82 \%(9 / 11)$, and $62 \%$ $(21 / 34)$, respectively. Success rates at 6 months postoperatively and at final visits were not significantly different in the two groups. Reoperations were performed in five patients in the $\mathrm{X}(\mathrm{T})$ group; four for recurrent exotropia, and one for consecutive esotropia, but no patient in the XT group needed reoperation.

Other than exotropia, inferior oblique muscle overaction (IOOA) was found in 12 of the 45 patients $(27 \%)$, SOOA in $2(4 \%)$, and DVD in $6(13 \%)$ patients. No significant intergroup difference was found between the prevalences of IOOA, SOOA, or DVD (Table 3). Eight of the forty-five patients (18\%) underwent surgical correction for associated ocular motility disorders; five for IOOA, two for SOOA, and one for DVD. No patient showed manifest or latent nystagmus.

Binocularity testing was performed in 34 patients; 7 in the $\mathrm{XT}$ group and 27 in the $\mathrm{X}(\mathrm{T})$ group. All 34 patients had gross stereopsis and 10 patients (29\%) developed bifoveal fixation (stereopsis of $60^{\prime \prime}$ or better). No significant difference was observed between sensory outcomes in the two groups (Table 4).

\section{Discussion}

Exodeviation in a healthy child younger than 1 year old is known to be rare, and few studies have addressed this disease entity. In 1983, Hiles and Biglan ${ }^{6}$ first used the term 'infantile exotropia' in their report of 28 patients with early-onset exotropia who received surgery before 24 months. In 1988, Rubin et $a l^{7}$ defined infantile exotropia as a condition characterized by a large angle and constant exotropia, which begins during the first year of life in an otherwise healthy child. Studies of infantile exotropia have shown a trend toward the inclusion of patients with intermittent deviation since the mid-1990s, whereas only constant exotropia patients were included in earlier studies. ${ }^{6-9}$

Early studies reported that, although successful motor alignment is achieved by surgery, it is difficult to achieve binocular single vision in infantile exotropia. $3,8,9$

However, sensory outcomes have been somewhat better in recent studies of infantile exotropia. Hunter et al ${ }^{4}$ reported that 7 of 10 testable patients $(70 \%)$ achieved gross fusion (fusion response on Worth 4-dot near testing or stereo fly perception) and Paik et $a l^{5}$ reported that 7 of 11 testable patients $(64 \%)$ developed stereopsis of $200^{\prime \prime}$ or better.

Choi and $\mathrm{Kim}^{10}$ recently classified early-onset exotropia patients on the basis of stereopsis outcome. Patients who showed excellent stereopsis of $\geq 60^{\prime \prime}$ were defined as early-onset intermittent exotropia group, whereas patients with stereopsis of $\leq 80^{\prime \prime}$ were classified as primary infantile exotropia group. In their study, 50\% of early-onset exotropia patients presented as constant exotropia, and 2 of 12 patients (17\%) with constant exotropia showed bifoveal fixation. In present study, 10 patients $(29 \%)$ of early-onset exotropia achieved bifoveal fixation, and it is noteworthy that sensory 
Table 3 Associated features other than exotropia

\begin{tabular}{lcccc}
\hline & $\begin{array}{c}\text { Entire group } \\
(\mathrm{n}=45)\end{array}$ & $\begin{array}{c}\text { Constant XT } \\
(\mathrm{n}=11)\end{array}$ & $\begin{array}{c}\text { Intermittent XT } \\
(\mathrm{n}=34)\end{array}$ & P-value $^{*}$ \\
\hline DVD & $6(13 \%)$ & $2(18 \%)$ & $4(12 \%)$ & 0.624 \\
IOOA & $12(27 \%)$ & $4(36 \%)$ & $8(24 \%)$ & 0.448 \\
SOOA & $2(4 \%)$ & $1(9 \%)$ & $1(3 \%)$ & 0.433 \\
\hline
\end{tabular}

Abbreviations: DVD: dissociated vertical deviation; IOOA: inferior oblique overaction; SOOA: superior oblique overaction; XT, exotropia.

${ }^{*} P$-value refers to intermittent versus constant XT.

Table 4 Results of the binocular vision assessment

\begin{tabular}{lcccc}
\hline & $\begin{array}{c}\text { Entire group } \\
(\mathrm{n}=34)\end{array}$ & $\begin{array}{c}\text { Constant XT } \\
(\mathrm{n}=7)\end{array}$ & $\begin{array}{c}\text { Intermittent XT } \\
(\mathrm{n}=27)\end{array}$ & P-value* \\
\hline $\begin{array}{l}\text { Gross } \\
\text { stereopsis } \\
<200 \mathrm{~s} \text { of }\end{array}$ & $34(100 \%)$ & $7(100 \%)$ & $27(100 \%)$ & \\
$\begin{array}{l}\text { arc } \\
\leq 60 \text { s of }\end{array}$ & $10(29 \%)$ & $5(71 \%)$ & $24(89 \%)$ & 0.268 \\
arc & $1(14 \%)$ & $9(33 \%)$ & 0.644 \\
\hline
\end{tabular}

Abbreviation: XT: exotropia.

${ }^{*} P$-value refers to intermittent versus constant XT.

outcome was not poor even in the patients who presented with constant exotropia.

As it is well known that slight overcorrection of exotropia during the early postoperative period produces best long-term results, ${ }^{11,12}$ our surgery intended to cause slight initial esotropia in all patients. When successful alignment after surgery was defined as orthophoria or alignment less than \pm 10 PD, success rates were not significantly different between our two study groups. This shows that the surgical prognosis is not as poor in early-onset exotropia, even in patients with constant deviation at presentation.

DVD is often related with early-onset exotropia, and reported incidences of DVD in infantile exotropia vary from 15 to $90 \% .^{3-5,7-9,13}$ In our study, DVD developed in six patients $(13 \%)$ and the XT group had a higher prevalence of DVD than the $\mathrm{X}(\mathrm{T})$ group; however, the difference in prevalence was not significantly different between the two groups. In addition, to DVD, oblique muscle dysfunction was found in 14 patients $(31 \%)$ and there was no difference in the prevalence between patients with constant or intermittent deviation.

Several limitations of our study deserve consideration. As the onset of the exodeviation of the patients relies on parental report and photographs, we could not confirm whether the deviation was constant or intermittent before 1 year of age or before the age at presentation. There is a possibility that some patients included in the XT group had a period of intermittent deviation before presentation, and this might have affected the sensory outcome in this group of patients. Therefore, it is not appropriate to compare our study results with that of previous series of early-onset exotropia in which the children were seen within the first year, and the distinction between constant and intermittent exotropia was made then. Our study only intended to compare the differences between the patients who presented with constant and intermittent deviation at initial visit. Relatively short follow-up periods could have been another study limitation and the long-term follow-up results should be evaluated in future studies.

Nevertheless, a large number of cases of early-onset exotropia were included in the present study.

In conclusion, no significant difference was found between early-onset exotropia patients who presented with constant or intermittent deviation. Most importantly, surgical outcomes and binocularity were similar for intermittent and constant exodeviation, which supports that even early-onset patients with constant deviation at presentation can have good motor and sensory outcome after surgery. Further studies are needed on natural history and clinical course of earlyonset intermittent exotropia, with an onset before 1 year of age.

\section{Summary}

\section{What was known before}

- Exotropia in a healthy child younger than 1 year of age is known to be rare and only limited studies are done on early-onset exotropia.

- Few patients presenting with onset of exotropia during the first year of life are known to achieve high-grade steopsis even after early surgical correction.

What this study adds

- Early-onset exotropia patients can have good motor and sensory outcome after surgery.

- Good binocular results following surgery can be achieved in children presenting even with apparently constant early-onset exotropia.

\section{Conflict of interest}

The authors declare no conflict of interest.

\section{Acknowledgements}

This work was supported by National Research Foundation of Korea Grant funded by the Korean Government (2009-0075636). 


\section{Author contributions}

S-YS: design and writing the article as the first author. MiK: conception and design of the article. JC: critical revision of the article. SK: design of the article and final approval of the article.

\section{References}

1 Von Noorden GK, Campos EC. Binocular vision and ocular motility. 6th ed. Mosby: St. Louis, 2002, pp 367.

2 Abroms AD, Mohney BG, Rush DP, Parks MM, Tong PY. Timely surgery in intermittent and constant exotropia for superior sensory outcome. Am J Ophthalmol 2001; 131: 111-116.

3 Biglan AW, Davis JS, Cheng KP, Pettapiece MC. Infantile exotropia. J Pediatric Ophthalmol Strabismus 1996; 33: 79-84.

4 Hunter DG, Kelly JB, Buffenn AN, Ellis FJ. Long-term outcome of uncomplicated infantile exotropia. J AAPOS 2001; 5: 352-356.

5 Paik HJ, Yim HB. Clinical effect of early surgery in infantile exotropia. Korean J Ophthalmol 2002; 16: 97-102.
6 Hiles DA, Biglan AW. Early surgery of infantile exotropia. Trans Pa Acad Ophthalmol Otolaryngol 1983; 36: 161-168.

7 Rubin SE, Nelson LB, Wagner RS, Simon JW, Catalano RA. Infantile exotropia in healthy children. Ophthalmic Surg 1988; 19: 792-794.

8 Biedner B, Marcus M, David R, Yassur Y. Congenital constant exotropia: Surgical results in six patients. Binocul Vision Eye Muscle Surg 1993; 8: 137-140.

9 Moore S, Cohen RL. Congenital exotropia. Am Orthopt J 1985; 35: 68-70.

10 Choi YM, Kim SH. Comparison of clinical features between two different types of exotropia before 12 months of age based on stereopsis outcome. Ophthalmology 2013; 120: 3-7.

11 Raab EL, Parks MM. Recession of the lateral recti: early and late postoperative alignments. Arch Ophthalmol 1969; 82: 203-208.

12 Kraft SP. Infantile exotropia. In: Rosenbaum AL, Santiago $\mathrm{AP}$ eds. Clinical Strabismus management: Principles and Surgical Techniques. WB Saunders: Philadelphia, 1993; pp 176-181.

13 Lee HW, Park SE, Oh SY. The clinical feature and surgical outcome of infantile exotropia. J Korean Ophthalmol Soc 2004; 45: 1899-1905. 